\title{
LA RESISTENCIA CONSTITUCIONAL Y LOS VALORES
}

La noción de resistencia constitucional que propongo en este ensayo y el análisis de las cláusulas constitucionales que la favorecen guardan relación de parentesco, pero no de identidad, con el concepto de rigidez, sólidamente elaborado por la doctrina, y con la función de las cláusulas de prohibición temporal de reforma, intangibilidad o rigidez máxima.

Uno y otro conceptos (rigidez y resistencia) derivan del principio de supremacía constitucional y tratan de resolver el problema político del conflicto entre la Constitución como poder constituyente objetivado y la voluntad democrática de cambio respecto al contenido de la Constitución que con el tiempo es previsible que surja. La duración de la Constitución parece ser el objetivo a conseguir.

La duración como vigencia formal es cosa distinta a la resistencia que trato de perfilar. Aquélla puede ser prolongada y referirse a una Constitución que no haya servido para nada ni haya calado apenas como constitución material. La Constitución española de 1876, obra del liberalismo doctrinario canovista, no se autodeclaraba dotada de vinculatoriedad inmediata, general y suprema, ni era rígida, y, por consiguiente no contenía procedimiento de reforma, ni procedía de un poder constituyente de soberanía ilimitada, pues en virtud del principio de respeto a la «Constitución interna» o constitución histórica, se entendía que la Constitución formal o escrita no era más que la glosa o especificación de aquélla ${ }^{1}$; de todo lo cual se derivaba,

${ }^{1}$ Luis Díez del Corral, «El liberalismo doctrinario», IEP, Madrid, $3^{\mathrm{a}}$. ed., págs. 457 y ss., en especial pág. 643. Esperanza Yllán Calderón, «Cánovas del Castillo entre la historia y la política», CEC, Madrid, 1985, en especial el capítulo sobre «La tradición ideológica del pensamiento canovista», págs. 85 a 129. Diego López Garrido, Estudios preliminar a su edición de «Discursos parlamentarios» de Antonio Cánovas del Castillo, CEC, Madrid, 1987, en especial «La alianza con la monarquía constitucional», págs XLVI a LIV. 
como el mismo Cánovas dijo en un discurso, que «la Constitución no es entre nosotros, sino una ley como otra cualquiera» ${ }^{2}$. Así devaluada, la Constitución de 1876 tuvo una larguísima duración, hasta 1931, o como mínimo hasta su «suspensión» por la Dictadura de Primo de Rivera en 1923. Sería ingenuo pensar que a pesar de su carácter ${ }^{3}$ y de su vaciamiento de contenido duró tanto, porque lo cierto es que duró tanto como consecuencia de su degradación y de su carácter meramente formal. Los procesos políticos inicialmente encauzados por los pactos políticos extraconstitucionales, pero nunca por la propia Constitución, quedaron siempre al margen de ella. Duró, pero no sirvió para organizar el Estado, reconocer derechos, estructurar la nación como sociedad política soberana y dar entrada pacífica a las nacientes exigencias de democracia que protagonizaban unos partidos dejados fuera del sistema. No fue un límite para el poder político, sino un cómodo instrumento en sus manos. Parece ser que en los años 1945 ó 1946, Franco encomendó a uno de los ministros de su mayo confianza que elaborase algo así como una Constitución de las que K. Löwenstein calificó como semánticas ${ }^{4}$, y como quiera que el ministro acometió la empresa no por cierto con entusiasmo democrático, pero sí con prisas, Franco le dijo: «Arrese no corras, que a mí me da lo mismo gobernar con la Constitución de 1876». Si una Constitución, como la citada, ni separa poderes, ni reconoce y garantiza derechos, ni encauza el juego político de las fuerzas reales en la sociedad, puede resultar muy cómodo gobernar con ella, con ella como máscara, porque no se gobierna según ella o vinculados a ella, pues no actúa como límite ni ejerce resistencia, frente al poder, ni organiza los poderes del Estado, ni encauza la realidad política, ni garantiza los derechos que declara. Por eso ha podido decirse con toda razón que Cánovas creó «el sistema más irreal de la historia de España» ${ }^{5}$.

Resistencia no equivale, pues, a duración, ni a resistir el paso del tiempo. Pero la resistencia implica poder constituyente democrático: la voluntad política de a) estructurar el ordenamiento jurídico merced al principio de jerarquía normativa con la Constitución como norma de las normas; b) reconocer y garantizar derechos fundamentales, vigentes ex Constitutione y protegidos jurisdiccionalmente,

\footnotetext{
${ }^{2}$ Diario de Sesiones, Congreso, día 7 de marzo de 1888, pág. 1659.

${ }^{3}$ James Brice, «Constituciones flexibles y Constituciones rígidas», Estudio preliminar de Pablo Lucas Verdú, CEC, Madrid, 1988.

${ }^{4}$ Karl Löwenstein, «Teoría de la Constitución», Ed. Grijalbo, Barcelona, 1944, Barcelona, 1979, págs. 218-222.

${ }^{5}$ Paul Preston, «Franco, Caudillo de España», Ed. Grijalbo, Barcelona, 1994, pág. 657. Azaña, «Obras completas», México, 1966, I, 627.
} 
y c) que el sistema de poderes del Estado y los derechos de los ciudadanos tengan vigencia efectiva y, en consecuencia que el juego político de todo ello resultante quepa realmente en la Constitución, no queden al margen de ella más fuerzas que las que se autoexcluyan y, en definitiva, que la dinámica realidad política sea encauzada por la Constitución de forma estable y no efímera. La resistencia sería algo así como duración efectiva de la Constitución y pondría de manifiesto el éxito del poder constituyente al haber acertado a elaborar un texto adecuado a la voluntad democrática del momento inicial, pero también dotado de mecanismos técnicos capaces de adaptarlo a las cambiantes preferencias democráticas del pueblo soberano.

2) La rigidez de la Constitución protege su supremacía y procura su duración a través de distintos mecanismos. Uno puede ser la prohibición de reforma durante un período determinado: tres Legislaturas según la Constitución francesa de 1791, ocho años según el artículo 375 de la Constitución de Cádiz, diez con arreglo el artículo 30 de la argentina de 1853. El artículo 200 de la francesa de 1791 justificaba ese paréntesis como adecuado al interés nacional, según el cual sólo conviene reformar aquellos artículos sobre los cuales la experiencia hubiera hecho sentir sus inconvenientes. No sirvió para nada: la Constitución saltó toda ella víctima de la dinámica revolucionaria ${ }^{6}$. Durante la discusión en el pleno de las Cortes de Cádiz del Proyecto elaborado por la Comisión de Constitución, el entonces artículo 373 (luego pasó a ser 375) fue objeto de larga discusión. No interesa reproducirla, pero sí recordar el planteamiento del problema hecho por Dou i de Bassols y la respuesta de Argüelles que finalmente prosperó como sustento del texto aprobado. Dijo Dou: «¿Con qué razón quitaremos nosotros a la nación y a las Cortes venideras un derecho que es incontestable?» Contestó Argüelles: «por último, Señor, la experiencia es la que nos ha de enseñar si es necesaria la variación, porque ella es la que puede acreditar lo perjudicial de un artículo. ¿Y qué será más esencial, Señor, que la Constitución se ponga en práctica, y que por ocho años los españoles manifiesten su opinión, conforme a las observaciones que hayan hecho en favor o en contra de los artículos, o que se varíen éstos mañana o esotro día sin estas observaciones?» ${ }^{7}$. Juan Bautista Alberdi justificaba el artículo 30 de la Constitución de Argentina de 1853 como medio «para garantirse contra las veleidades inagotables

\footnotetext{
${ }^{6}$ Leon Duguit, H. Monnier, R. Bonard, «Les Constitutions et les principales lois politiques de la France depuis $1791 », 7^{\mathrm{a}}$. ed., París, 1952, págs. 31-32.

${ }^{7}$ Diario de Sesiones, día 17 de enero de 1812, págs. 2.643-2.644.
} 
de la demagogia que se veían venir y que tantas veces nos han impedido tener Constitución....» ${ }^{8}$. Pero lo cierto es que ni el artículo 375 de la Constitución de Cádiz supuso un freno para Fernando VII, ni la Argentina de 1853 evitó con su artículo 30 la reforma de 1860 con el objeto de que Buenos Aires entrara en la Federación. La cláusula de prohibición temporal e inicial de reforma puede justificarse diciendo que significa una prolongación del proceso constituyente o la existencia durante ese período de un «poder constituyente abierto» ${ }^{9}$. En todo caso, las justificaciones coetáneas o posteriores, no palian el fracaso de tales medidas: una rigidez excesiva puede incluso invitar a la supresión de la Constitución o a su sustitución por otra completamente distinta y no garantiza por sí misma la duración de la vigencia de la Constitución. En la práctica del constitucionalismo moderno se han abandonado tales prohibiciones temporales de reforma.

Las cláusulas de intangibilidad impiden sin sujeción a límite temporal la reforma de determinados preceptos constitucionales. Los procedimientos agravados de reforma, más complejos y difíciles que el procedimiento simple de reforma (a su vez, como es obvio, distinto y más tortuoso que el legislativo ordinario) plantean el problema democrático apuntado sin tecnicismos por Dou i de Bassols en las Cortes de Cádiz, y que en la formulación que le dio Ignacio de Otto consiste en el enfrentamiento entre el principio de equivalencia de opciones propio de un sistema democrático y el principio de preferencia en favor de la adoptada por la Constitución en los preceptos intangibles. La justificación democrática de la limitación de la democracia sólo puede encontrarse en favor de aquellos preceptos constitucionales que contienen la fundamentación de la democracia misma como sucede con los derechos fundamentales ${ }^{10}$. Esta justificación se debilita o puede llegar a faltar si la cláusula de intangibilidad protege instituciones menos o nada consustanciales con la democracia misma. El razonamiento es válido, «mutatis mutandis», a propósito de los procedimientos agravados de reforma y de las normas constitucionales por ellos convertidas en especialmente rígidas ${ }^{11} \mathrm{y}$, por consiguiente, en normas de duración privilegiada, puesto que es la conservación máxima en el tiempo de determinadas decisiones

\footnotetext{
${ }^{8}$ Juan Bautista Alberdi, «Estudios sobre la Constitución argentina de 1853», nueva edición oficial, Besanzon, 1858, pág. CIX.

${ }^{9}$ Germán J. Bidart Campos, «Tratado elemental de Derecho Constitucional argentino», nueva edición, tomo I, EDIAR, Buenos Aires, 1944, págs. 192 y 195.

${ }^{10}$ Ignacio de Otto, «Derecho Constitucional. Sistema de fuentes», Ariel-Derecho, Barcelona, 1987, págs. 59-61.

${ }^{11}$ Pedro de Vega, «La reforma constitucional y la problemática del poder constituyente», Ed. Tecnos, Madrid, 1985, págs. 217 a 303 y también págs. 53 a 75.
} 
políticas fundamentales tomadas por el constituyente lo que se procura con estos mecanismos de rigidez agravada o de simple e indefinida intangibilidad.

3) La resistencia de la Constitución puede ser entendida como adaptabilidad a la dinámica política, permitiendo y encauzando que las diversas opciones políticas puedan alcanzar el poder o los poderes del Estado y convertir en derecho del Estado las distintas expectativas pragmáticas por ellas ofrecidas a los ciudadanos ${ }^{12}$. También como su capacidad para ser interpretada de forma flexible y hasta cierto punto cambiante en función de nuevos problemas y nuevas sensibilidades o exigencias a propósito de los derechos fundamentales en ella positivizados pero no definidos. Y además, como resistencia a la reforma, haciéndola innecesaria.

Si la rigidez implica prohibición o dificultad de reforma del texto de la Constitución, resistencia significa adaptabilidad al cambio haciendo innecesaria la reforma. Resistir es oponerse un cuerpo a la fuerza de otro, tolerando o aguantando su empuje sin romperse. La resistencia constitucional ha de ser elástica, consiste en asimilar, sin dejarlas fuera, las distintas expectativas políticas no frontalmente opuestas a su texto y a su sentido sistemático, es decir, a la Constitución como un todo. Una Constitución está dotada de resistencia si es capaz de producir el acoplamiento entre la realidad jurídica normativa en que ella misma consiste y la siempre cambiante realidad política, es decir, en su capacidad para asumir mutaciones ${ }^{13}$. El resultado será la duración prolongada y sin reformas, o al menos sin necesidad de llevar a cabo reformas por el procedimiento agravado. Dado que las reformas o son imposibles o son más o menos traumáticas, la resistencia como capacidad para asumir mutaciones sin desvirtuarse, parece una cualidad, y en el momento constituyente una finalidad digna de ser favorecida por determinadas medidas incluidas en el texto constitucional, que aunque pueden cumplir otras funciones incluso más importantes pueden servir para lograr una eficacia duradera y flexible de la Constitución.

Creo que puede formularse la hipótesis de que una Constitución dotada de mecanismos acertados para hacerla resistente en el sentido expuesto, protege su supremacía y alcanza una vigencia efectiva y una duración prolongada, sin tener que pagar el precio de las reformas agravadas. Con referencia a la Constitución española de 1978 analizaremos en ese marco el papel que han cumplido y cumplen los

\footnotetext{
${ }^{12}$ I. de Otto, «Derecho...», págs. 39 y ss.

${ }^{13}$ P. de Vega, pág. 180 y en general, 179 a 2.081.
} 
valores y principios positivizados en la Constitución dentro de la jurisprudencia del Tribunal Constitucional $^{14}$.

4) Kelsen, hablando del carácter racionalista de la democracia hablaba en un pasaje famoso de la tendencia propia del Estado democrático a procurar, «mediante un Derecho preestablecido», que los actos de los órganos administrativos y de los tribunales «resulten -en cuanto sea posible- previsibles». Y cierra el párrafo con esta frase lapidaria: «La seguridad jurídica, más que la justicia absoluta, ocupa el primer plano en la conciencia jurídica» ${ }^{15}$. Sorprende en este contexto el adjetivo "absoluta», casi excluido del pensamiento democrático del último Kelsen, pero no es en ese punto el ahora interesante, sino el de la previsibilidad en cuanto sea posible de los actos de los tribunales (dejemos a la Administración a un lado). Porque si no es del todo posible preverlos, es claro que la seguridad jurídica, cualquiera que sea el lugar que ocupe en la conciencia de los juristas tampoco será «absoluta». Por lo demás la obra de Kelsen está llena de referencias al imposible automatismo del juez, a su papel mucho más complejo que el de productor de silogismos, a su función de creador de normas individuales y a la discrecionalidad que todo juez forzosamente ha de tener y debe tener ${ }^{16}$. La seguridad jurídica al cien por cien sólo es concebible en un ordenamiento jurídico petrificado, de foto fija, y cuyos aplicadores no fuesen intérpretes, sino autómatas. Si el ordenamiento debe dar respuesta a realidades cambiantes sin necesitar cambiar continuamente sus normas generales y últimas, necesita de intérpretes dotados de discrecionalidad. Si de la Constitución hablamos, que no es una ley cualquiera, y de su intérprete supremo, que no es un juez como los demás, la seguridad acerca de la Constitución ha de ser compatible con su capacidad para asimilar mutaciones por vía jurisdiccional, con lo cual las Sentencias del Tribunal Constitucional y en ellas más que sus fallos su doctrina y la interpretación adquieren singular importancia. Quizá no siempre, no en todos los casos por igual. También hay «casos rutinarios» en el trabajo cotidiano de un Tribunal Constitucional: precisamente aquellos que le permiten repetir su propia jurisprudencia,

${ }^{14}$ Por supuesto sin pretensiones monográficas o exhaustivas, sino más bien ejemplificantes.

${ }^{15} \mathrm{H}$. Kelsen, «Los fundamentos de la democracia» (1954) incluido en «Escritos sobre la democracia y la sociedad», Editorial Debate, Madrid, 1988, págs. 207 y ss., en particular, 244-245.

${ }^{16}$ Ibídem, págs. 310-314. H. Kelsen, «Teoría general del Derecho», trad. L. Legar Lacamba, Ed. Nacional, Madrid, 1979, págs. 301-307. H. Kelsen, «Teoría pura del derecho», trad. de R. J. Vernengo de la Ed. de Viena 1960, UNAM, México, 1978, págs. 246 a 263. 
de modo tal que, si rutinarios, son inútiles y justificarían en determinadas circunstancias el writ of certiorax. Los hoy casos rutinarios tienen como primer o primeros eslabones de la cadena «casos difíciles», y en la primera etapa de un Tribunal Constitucional todos sus casos son por fuerza casos difíciles, si por tal entendemos aquellos o aquel «en el que no hay una norma establecida que dicte una decisión en ningún sentido» ${ }^{17}$, puesto que, ciertamente ahí estaba la Constitución como norma suprema y norma de normas y conjunto ella misma de normas, pero nadie antes del primer caso de cada serie de problemas la había interpretado, ni había dicho cuál era la norma aplicable, ni cuál su significado. El juez constitucional está vinculado por la seguridad jurídica; si del español se trata esa vinculación le viene dada por el propio artículo 9.3 de la Constitución. Pero tiene sobre sí otras obligaciones entendidas como funciones del órgano al que pertenece. Tiene que hacer servible la Constitución, proteger el poder constituyente objetivado en ella, lograr que dé respuesta a problemas no previstos expresamente, resolver ambigüedades y aun aparentes contradicciones acudiendo a una interpretación sistemática y a la noción de la Constitución como un todo. Para ello ha de dar sentido explícito a términos sólo enunciados, ha de precisar los significados precisos de unos significantes casi mudos, ha de fijar límites recíprocos entre derechos en conflicto. Para valorar académicamente el razonamiento de una Sentencia de un Tribunal Constitucional dudo que valgan ni lo que Dworkin llama «retórica de la facultad de Derecho» ${ }^{18}$, ni el olvido de que, siendo la Constitución, por su contenido material (derechos) y no sólo procedimental, una ley política cargada de contenido ético, el juez constitucional con frecuencia, con mucha frecuencia si se trata de un Tribunal casi recién nacido, ha de enfrentarse con decisiones nuevas cuya solución implica poner en juego «la moralidad política propia de cada juez», integrante del órgano colegiado que es intérprete supremo de la Constitución ${ }^{19}$. Pues bien, para esta delicada tarea son de utilidad máxima la positivación por la propia Constitución, en nuestro caso la española de 1978, de una lista de valores y principios, aquéllos incluso jerarquizados, colocando como superiores los cuatro enunciados en el artículo $1.1 \mathrm{y}$ muy cerca de ellos la dignidad de la persona de la que habla el artículo 10.1 CE. En cuanto a los principios, y dejando aparte los principios rectores del artículo 39 y siguientes, que cumplen otra función, la Constitución contiene una

\footnotetext{
${ }^{17}$ Ronald Dworkin, «Los derechos en serio», Ariel, Barcelona, 1989. págs. 146 y ss., en particular pág. 149.

${ }^{18}$ R. Dworkin, op. y loc. cit. pág. 153.

${ }^{19}$ R. Dworkin, Ibídem.
} 
larga serie de ellos (los del artículo 9.3, los de autonomía y solidaridad derivados de los artículos 2 y 138, los de igualdad y progresividad del sistema tributario del artículo 31 etcétera) afines, pero no confundibles con los valores, ni todos ellos de la misma naturaleza ${ }^{20}$.

Lo que de unos y otros me interesa señalar es su utilidad jurisprudencial. Los principios sirven y obligan al intérprete para ajustar el engarce técnico entre preceptos constitucionales o entre ellos y normas infraconstitucionales sometidas a juicio declarativo de constitucionalidad. Los valores sirven y obligan al intérprete constitucional a incorporar a sus resoluciones, y en particular a sus razonamientos lo que Dworkin denomina «moralidad política ${ }^{21}$ y Gregorio Peces Barba «moralidad crítica» o también «objetivos éticos» ${ }^{22}$. Creo que la recta utilización jurisprudencial de estas categorías constitucionales, y en especial de los valores, favorece la resistencia constitucional en cuanto adaptabilidad o apertura a nuevas exigencias éticas concretas que sólo cabe considerar incorporadas como contenido de determinados derechos fundamentales en virtud de la cobertura amplia y flexible que se deriva de tan generales, pero positivizadas, cláusulas. Fue un acierto innegable del constituyente incluir la apelación a los valores como normas. No sé si ha sido siempre acertada o no la invocación por parte del Tribunal Constitucional a los valores del $1.1 \mathrm{y}$ del 10.1. Nadie debe ser juez y parte. También sé que para algunos las citadas cláusulas constitucionales introducen elementos de inseguridad jurídica, «metiendo la filosofía en el Derecho», como en cierta deliberación oí decir a un juez constitucional, por lo demás excelente. Pero estoy convencido del muy fecundo papel que los valores constitucionalizados como normas han cumplido en la jurisprudencia del Tribunal Constitucional, que, sin convertirse en lo que no puede ser y algunos temían (id est, en una jurisprudencia de valores) que fuera, ha podido con su ayuda resolver casos concretos yendo con ellos más allá de una interpretación fácil y rutinaria de los límites y contenidos de los derechos fundamentales. La tríada de conceptos «Derecho-Moral-Política» no está formada por tres esferas aisladas, sino por tres eslabones de una cadena: los valores constitucionalmente positivizados como normas ayudan a fortalecer la conexión entre los eslabones y a hacer más resistente la cadena.

Mientras que el constitucionalismo norteamericano tiene abierto el dilema entre la interpretación literalista de la Constitución u otra

${ }^{20}$ Gregorio Peces Barba, «Los valores superiores», Ed. Tecnos. Madrid, 1984, contiene una distinción entre ellos a la que me remito: ibíd, pág. 34 y ss.

${ }^{21}$ Op. y loc. cit., pág. 153.

${ }^{22}$ Op. y loc. cit., págs. 18 y 51. 
más abierta que permita al Tribunal Supremo aplicar los «valores fundamentales» implícitos en su Constitución ${ }^{23}$, la española de 1978 al positivizar unos valores, los del 1.1 y hacerlos vinculantes como superiores y generales a todo el ordenamiento opta por una determinada línea interpretativa y explicita cuáles son sus valores. Como sostuvo en su momento Enterría, entre nosotros «esta calificación no es baladí, ni es tampoco un simple prurito estático de los juristas, sino que implica el destacamiento como básica de esta decisión constitucional, en el sentido de C. Schmitt, lo que revela en el plano estrictamente técnico el artículo 168 de la Constitución que equipara la alteración de estos valores superiores a la adopción de una nueva Constitución. Ello implica, forzosamente, una posición dominante y de supremacía de estos <valores superiores> en la interpretación de todas las demás normas constitucionales, y aún la posibilidad, no sólo hipotética, de calificar desde los mismos como inconstitucionales normas constitucionales actuales o futuras $»^{24}$.

Otto Bachof se preguntaba, en su justamente famosísima conferencia cómo podía explicarse el elevado número de sentencias del BVG derogando leyes antiguas por entrar en contradicción con la Constitución de 1949 y se contestaba así: «No se puede explicar más que por la enérgica pretensión de validez de las normas materiales de nuestra Constitución; por una orden de valores, que vincula directamente a los tres poderes estatales, tal como se manifiesta expresamente en la regulación de los derechos fundamentales». La ventaja de nuestra Constitución respecto a la Ley Fundamental de Bonn es el mejor grado de explicitación y de jerarquía que tales valores alcanzan en la nuestra ${ }^{25}$.

Los juristas educados en un mal entendido positivismo y en una cómoda confusión entre interpretación y literalidad reprocharán siempre la inconcreción y vaguedad de las cláusulas constitucionales que positivizan determinados valores. La mejor respuesta a sus reticencias es quizá un texto del juez Hulestedler que cita Capelletti, repite Enterría y yo vuelvo a trasladar al posible lector:

«No es con ironía como yo califico los términos del Bill of Rights de ambigüedades gloriosas. La naturaleza inasible de su substancia ha hecho posible la determinación y la redeterminación

${ }^{23}$ John H. Ely, «Democracy and disfrust. A theory of judicial revieu», 1980.

${ }^{24}$ Eduardo García de Enterría, «La posición jurídica del Tribunal Constitucional español: posibilidades y perspectivas», ahora en «La Constitución como norma y el Tribunal Constitucional», Ed. Civitas, 1981, la cita en pág. 144.

${ }^{25}$ Otto Bachof, «Jueces y Constitución», Ed. Civitas, Madrid, 1985, pág. 39. En el mismo sentido de mi afirmación, cfr. Gregorio Peces Barba. «Los valores...», págs. 68 y 124-125. 
de la doctrina constitucional de manera que satisfaga las necesidades de una sociedad libre, pluralista y en evolución. Mientras que la precisión ocupa una plaza de honor en la redacción de un Reglamento de la autoridad local de policía, es mortal cuando se trata de una Constitución que quiera ser viva» ${ }^{26}$.

Valores sobre derechos: ambigüedad de ambigüedades, tal vez. Pero una interpretación constitucional que sea al mismo tiempo autorrestrictiva, congruente (o coherente consigo misma, en el sentido de Dworkin) y creativa cuando la realidad del problema le obligue a ello puede extraer enormes virtualidades de esas cláusulas que podrán servir para moralizar el Derecho y para mantener viva y resistente la Constitución.

5) El Tribunal Constitucional ha hecho numerosas declaraciones sobre la vinculatoriedad de los valores del $1.1 \mathrm{y}$ del $10.1 \mathrm{y}$ acerca de los derechos fundamentales como concreción de ese sistema axiológico o de algún valor concreto. Peces Barba ${ }^{27}$ recogió en su libro citado algunas de esas declaraciones. Hay otras posteriores. Sin pretender una recopilación completa ni, menos aún, un estudio crítico de ellas, expondré algunas de las más significativas. Finalmente, analizaré una Sentencia del Tribunal en la que la invocación a valores fue un elemento fundamental de su «ratio decidendi». En realidad, la cita de declaraciones jurisprudenciales sobre el par de conceptos valores -derechos trata de servir como base a la afirmación de que el recurso a valores que el T. C. hizo en la Sentencia 214/1991, que será analizada, no está fuera de contexto dentro de lo que pudiéramos llamar declaraciones teóricas sin aparentes efectos decisorios.

El Tribunal Constitucional ha dicho que «los derechos y libertades fundamentales son elementos del ordenamiento, están contenidos en normas jurídicas contenidas que forman parte de un sistema axiológico positivizado por la Constitución y constituyen los fundamentos materiales del ordenamiento jurídico entero ${ }^{28}$. Por eso, y teniendo en cuenta «que la Constitución incorpora un sistema de valores cuya observancia requiere una interpretación finalista de la Norma Fundamental» los preceptos que contienen derechos fundamentales

${ }^{26}$ Op. cit. en nota 25 , pág. 229.

${ }^{27}$ «Los valores...», págs. 123 y ss. 146, 157-158.

${ }^{28}$ En rigor esto no lo dijo el Tribunal, sino uno de sus magistrados en su voto particular disidente contra la STC 5/1981, pero sobre este punto no hubo desacuerdo, como se comprobará por su coincidencia sustancial con los textos que siguen. Cfr. «Jurisprudencia Constitucional», I, pág. 104. [En adelante cito por número de la Sentencia, año, tomo y página]. 
no pueden ser objeto de una «aplicación literal», sino que han de ser aplicables a cada caso «en la medida necesaria para preservar los valores esenciales que se encuentran en la base del precepto» ${ }^{29}$.

$\mathrm{Y}$ es que no cabe desconocer «que los derechos fundamentales responden a un sistema de valores y principios de alcance universal que subyacen a la Declaración Universal y a los diversos convenios internacionales sobre derechos humanos ratificados por España, y, que, asumidos como decisión constitucional básica, han de informar todo nuestro ordenamiento jurídico ${ }^{30}$.

Valores y derechos fundamentales van, pues, unidos por relación de derivación o proyección: «es indudable que muchos de los derechos fundamentales y libertades públicas tutelables en amparo son proyecciones del valor libertad, pero sólo estas proyecciones concretas crean derechos amparables en esta vía procesal» ${ }^{31}$.

Junto a los valores del art. 1.1. los del artículo 10.1: «Indisociablemente relacionado con el derecho a la vida en su dimensión humana se encuentra el valor jurídico fundamental de la dignidad de la persona reconocido en el artículo 10 como germen o núcleo de unos derechos que le son inherentes». Analizados los artículos 10, 15, 16 y 18.1, el Tribunal llega a la conclusión de que «del sentido de estos preceptos puede deducirse que la dignidad es un valor espiritual y moral inherente a la persona, que se manifiesta singularmente en la autodeterminación consciente y responsable de la propia vida y que lleva consigo la pretensión al respecto por parte de los demás ${ }^{32}$.

¿Es todo esto música celestial que suena bien, pero permanece recluida en lejanas y no terrestres esferas? Es sólo «retórica de la Facultad de Derecho», vicio profesional de un Tribunal compuesto

hasta ahora en su gran mayoría por profesores y no por jueces «de carrera»? Es posible que así lo hayan entendido algunos exegetas, pero no el propio Tribunal.

En un recurso de amparo contra dos resoluciones judiciales que hablaban de «la justicia material» como algo externo al ordenamiento, el Tribunal dijo: «la justicia no es un valor ajeno y contrario al ordenamiento positivo, sino uno de los valores superiores del mismo. No es lícito sacrificar el cumplimiento de una norma constitucional <todos tienen derecho a ser informados de la acusación formulada contra ellos $>$ art. 24.2 CE) en aras de una $<$ justicia material $>$ que, entendida como algo contrapuesto a la Constitución, sería un

${ }^{29}$ STC 18/1981, II, págs. 37-38.

${ }^{30}$ STC 21/1981, II, pág. 71.

${ }^{31}$ STC 120/1990, XXVII, pág. 431.

${ }^{32}$ STC 53/1985, XI, págs. 573 y 576. 
concepto metajurídico inadmisible para el juzgador. Lo que la Sentencia de la Sala Segunda del Tribunal Supremo denomina incongruencia por exceso cometida al condenar a un procesado por unos hechos que no fueron objeto de acusación constituye una violación de una de las garantías principales del proceso penal configurada en nuestra Constitución como un derecho de todos. Se trata, ciertamente, de una garantía formal, pero es a través del respeto y del celoso cumplimiento de tales garantías como se ha de perseguir en el proceso la justicia como valor» ${ }^{33}$.

Los valores y los principios constitucionalizados son normas positivas, no son música celestial. Por lo mismo el Tribunal no duda de que «como regla general los valores superiores del ordenamiento y los principios constitucionales pueden bastar para promover recursos o plantear cuestiones de inconstitucionalidad $»^{34}$.

6) El Tribunal Constitucional garantiza la supremacía de la Constitución de modo principal y directo a través del control de constitucionalidad de las leyes. Ejerciendo su «monopolio de rechazo» hace viable el funcionamiento de la estructura autonómica del Estado resolviendo los conflictos de competencia de acuerdo con las normas del «bloque de la constitucionalidad». Pero quizá la vía del recurso de amparo sea la que le permita mejor cumplir la función de adecuar la Constitución a problemas no previstos «ab initio» que surgen en la dinámica política de algunas instituciones centrales del sistema, así como a exigencias de moralidad política planteadas en el seno de la sociedad. Entre las primeras pensemos, por ejemplo, en el juramento de los diputados de Herri Batasuna, a propósito de cuyo recurso de amparo el Pleno dijo entre otras cosas las siguientes como fundamento del otorgamiento de su amparo:

«El requisito del juramento o promesa es una supervivencia de otros momentos culturales y de otros sistemas jurídicos a los que era inherente el empleo de ritos o fórmulas verbales ritualizadas como fuentes de creación de deberes jurídicos y de compromisos sobrenaturales. En un Estado democrático que relativiza las creencias y protege la libertad ideológica; que entroniza como uno de sus valores superiores el pluralismo político; que impone el respeto a los representantes elegidos por sufragio universal en cuanto poderes emanados de la voluntad popular; no resulta congruente una interpretación de la obligación de

${ }^{33}$ STC 20/1987, XVII, pág. 196.

${ }^{34}$ STC 116/1987, XVIII, pág. 615. 
prestar acatamiento a la Constitución que antepone un formalismo rígido a toda otra consideración, porque de ese modo se violenta la misma Constitución de cuyo acatamiento se trata, se olvida el mayor valor de los derechos fundamentales (en concreto, los del art. 23) y se hace prevalecer una interpretación de la Constitución excluyente frente a otra integradora ${ }^{35}$.

En esta misma línea jurisprudencial podrían citarse varias sentencias en recursos de amparo electoral del artículo 49 de la LOREG, o más en concreto algunas ${ }^{36}$ que resolvieron amparos ordinarios como punto final de impugnaciones por la vía contencioso-administrativa contra proclamación de resultados electorales.

En Sentencias como las ahora citadas se pone de manifiesto lo que significa la interpretación creativa como método jurisprudencial para resolver desde y según la Constitución y con argumentos jurídicos entre los que se incluyen invocaciones a los valores positivizados por ella, problemas políticos frente a cuyo embate o desafío la Constitución ha de ser resistente y cumplir una función integradora.

En ocasiones, sin embargo el desafío al contenido material de la Constitución surge en el seno de la sociedad y como consecuencia del ejercicio de derechos fundamentales en conflicto. Así sucedió en el caso de Violeta Friedman resuelto por el Tribunal en noviembre de $1991^{37}$ y al que paso a referirme comenzando por sintetizarlo en atención al posible lector de estas páginas.

Leon Degrelle formuló en una revista unas declaraciones en menosprecio del pueblo judío, alabanza de Hitler y del doctor Mengele y poniendo en duda la existencia de los hornos crematorios en los campos de exterminio. Violeta Friedman demandó al declarante y a la revista por entender que había sido lesionado su honor porque ella misma estuvo internada en Auschwitz y toda su familia pereció allí gaseada por orden del citado doctor Mengele. Los órganos del orden jurisdiccional civil ante los que la actora judía formuló su demanda de protección al honor le negaron la legitimación activa por cuanto en las citadas declaraciones no se la mencionaba a ella ni a sus familiares, por lo que sus resoluciones, impugnadas, en demanda de amparo constitucional después no entraron en el análisis de la pretensión de fondo. El Tribunal Constitucional reconoció la legitimación activa de la demandante por entender que «el significado personalista que el derecho al honor tiene en la Constitución no impone que los ataques o lesiones al citado derecho fundamental,

\footnotetext{
${ }^{35}$ STC 119/1990, XXVII, págs. 387-417. «El texto», pág. 416.

${ }^{36}$ STC 24/1990, 25/1990 y 26/1990, XXVI, págs. 240-325.

${ }^{37}$ STC 214/1991, XXXI, págs. 444-446.
} 
para que tengan protección constitucional, hayan de estar necesariamente perfecta y debidamente individualizados ad personam». Entrando en el fondo del asunto otorgó el amparo a la recurrente por entender que las manifestaciones del señor Degrelle constituyeron una «intromisión ilegítima en el honor y dignidad de la hoy recurrente de conformidad con lo dispuesto en los artículos 1.1, 10.1 y $18.1 »$ de la Constitución.

Manuel Atienza comenzó críticamente ${ }^{38}$ la Sentencia censurando la decisión del Tribunal que le parece equivocada en términos de razonamiento jurídico, al margen de las [buenas] intenciones morales de los cinco magistrados de la Sala Primera que la sostuvieron con su voto ${ }^{39}$.

Estoy de acuerdo con Atienza en algunas de sus afirmaciones, pero no en su desacuerdo principal que gira, si lo entiendo bien, en la relación entre argumentación jurídica y argumentación moral y en la plasmación de los términos de ese binomio en el razonamiento y en la «ratio decidendi» del Tribunal. Comparto su afirmación de que el Derecho ha de ser «consciente de sus límites», aunque subrayo que el problema reside en trazarlos. Comprendo que «el Derecho nunca podrá sustituir a la moral», ni lo pretendo ni creo que el Tribunal lo haya pretendido nunca, pero creo que sí es conveniente aproximar el uno a la otra en determinadas circunstancias, condiciones y modos, siendo la palabra determinadas, es decir, la determinación del cuándo y el cómo de la aproximación, lo problemático. También estaría dispuesto a aceptar sus consideraciones acerca del juez como aplicador del Derecho, si se refirieran a un juez que no fuese el Tribunal Constitucional. En la parte última de su razonamiento creo percibir algunas afirmaciones puente entre su postura y la del Tribunal: así cuando reconoce que «en los casos jurídicamente difíciles -como el caso Friedman- la argumentación jurídica contiene

${ }^{38}$ Manuel Atienza, «Tras la justicia. Una introducción al Derecho y al razonamiento jurídico», Ariel, Barcelona, 1933, págs. 36 a 61.

${ }^{39}$ Hubo un magistrado que formuló un voto particular disidente. Quien esto escribe presidió la Sala y votó a favor del proyecto presentado por el ponente y ampliamente debatido por la Sala. Cualquier acusación contra mí de actuar ahora como juez que juzgó y como defensor del juez que juzgó está, pues, justificada. Pero mi discrepancia con el discrepante, papel que asume de modo inteligente Manuel Atienza, me lleva a adoptar ese papel, ya y sólo en sede académica y cuando he dejado de ser magistrado del Tribunal. Por lo demás la exposición de mi discrepancia no va a producir como resultado que la sangre de nadie llegue a ningún río. Y ello no sólo porque ni en Madrid ni en Alicante hay caudales (sino a lo sumo cauces) de agua que merezcan tal nombre, sino porque ni el tono de Manolo Atienza ni el mío son agresivos. Aunque somos colegas y amigos, dos buenas razones para el despedazamiento recíproco en una polémica académica «more hispanico», ni su crítica ni mi discrepancia pretenden hacer daño, ni lo hacen, a nada ni a nadie. 
siempre, inevitablemente, juicios morales», pero me parece que tal expresión u otras semejantes y contiguas (como «consideraciones morales») tienen un matiz subjetivo, como referidas a las personales creencias de los integrantes de la Sala sentenciadora, siendo así, por el contrario, que la Sentencia en cuestión extrae sus consideraciones o juicios morales no del individual código ético de cada magistrado, sino de lo que la Constitución declara normativamente en los artículos que con reiteración se citan: el 1.1 y el 10.1 principalmente, y su concreción en el 14 de la Constitución.

Hay un párrafo en la Sentencia que constituye en verdad su «ratio decidendi» ${ }^{40}$, que Manuel Atienza no identifica como tal (a mi modo de ver en esta inadvertencia está la raíz de su discrepancia, o al menos la de la mía con la suya) y que por lo mismo no cita ni comenta. Es éste:

«La dignidad como rango o categoría de la persona como tal, del que deriva y en el que se proyecta el derecho al honor (art. 18.1 CE) no admite discriminación alguna por razón de nacimiento, raza o sexo, opiniones o creencias. El odio y el desprecio a todo un pueblo o a una etnia (a cualquier pueblo o a cualquier etnia) son incompatibles con el respeto a la dignidad humana, que sólo se cumple si se atribuye por igual a todo hombre, a toda etnia, a todos los pueblos. Por lo mismo, el derecho al honor de los miembros de un pueblo o etnia, en cuanto protege y expresa el sentimiento de la propia dignidad, resulta sin duda lesionado cuando se ofende y desprecia genéricamente a todo un pueblo o raza, cualesquiera que sean. Por ello, las expresiones o aseveraciones proferidas por el demandado también desconocen la efectiva vigencia de los valores superiores del ordenamiento, en concreto la del valor igualdad consagrado en el art. 1.1 de la Constitución en relación con el art. 14 de la misma, por lo que no pueden considerarse como constitucionalmente legítimas $\rangle^{41}$.

En esa interpretación conjunta de valores y derechos está la razón de la decisión y, sobre todo, el fundamento de la fijación de un límite a la libertad de expresión. Atienza dice que la libertad de expresión «puede afectar a otros valores (el honor de las personas, el orden público, etc.), pero no por la simple razón de que lo que se exprese se considere moralmente incorrecto» ${ }^{42}$. Cabría precisar que el honor

\footnotetext{
${ }^{40}$ Loc. cit. en nota 39 págs. 52 a 54, donde habla de la ratio decidendi de la sentencia y de su coherencia.

${ }^{41}$ Loc. cit. en nota 38, pág. 463.

${ }^{42}$ Loc. cit. en nota 39, pág. 53 in fine.
} 
de las personas no es un valor sino un derecho, y que eso del orden público más vale dejarlo aparte; pero por lo demás, excluido el paréntesis, su texto parece impecable: cabalmente eso es lo que hizo el Tribunal en su Sentencia 214/1991 y en otras muchas. De donde se infiere que el desacuerdo entre Atienza y la Sentencia es quizá más aparente que real y profundo.

Finalmente opina Atienza que el criterio del Tribunal en su Sentencia es ineficaz. Tal vez en un sentido inmediato no sea de eficacia arrolladora. No obstante esa «función latente» que Atienza reconoce a la decisión que él califica de equivocada en términos jurídicos, no es desdeñable, aunque sea lenta porque lenta es la pedagogía de los derechos y, sobre todo, la de sus límites. Pero estos límites, cuando de derechos fundamentales se trata, ha de trazarlos el Tribunal Constitucional valiéndose de los valores. 